ich die rhythmischen Eigenthtimlichkeiten der Bucher genau zu bezeichnen und mit den tubrigen Eigenthümlichkeiten in Zusammenhang zu setzen gesucht; auch habe ich auf den ästhetischen Werth derselben aufmerksam gemacht. Dieses und Anderes werden die Kenner nicht übersehen und mit Billigkeit prufen.

Berlin am Ende des Junius 1817.

\title{
Aus dem Vorworte zur sechsten Ausgabe.
}

Schneller als ich erwartet hatte, und mich in anderen schriftstellerischen Arbeiten unterbrechend trat die Nothwendigkeit ein diese sechste Auflage vorzubereiten. Gleichwohl habe ich der Aufgabe das unterdess in diesem Gebiete Erschienene zu vergleichen und zu berïcksichtigen nach Kräften zu gentigen gesucht, und so der Schriften von Hupfeld, Movers, Frankel, Stähelin, Ewald, von Lengerke, Hauff, Thenius, Hitzig, Friedrichsen, Caspari, Delitzseh, Burger, Hävernick, Herbst, Welte u. A. gebuhrende Erwähnung gethan. Sollte ich die eine oder andere ubersehen haben, so bitte ich um Entschuldigung. Wirklich ist dies der Fall mit H. W. J. Thierseh de Pentateuchi vers. alex. Erl. 1840. Auch muss ich nachträglich bemerken und empfehlen das fleissige nutzliche Werk: J. Kir ch h o fer Quellensammlung zur Gesch. d. neutest. Canons bis auf Hieronymus mit Anmerkungen vorztiglich für Studirende. Zür. 1844. Erst in diesen Tagen ist mir die Kunde zugekommen von der Vollendung der lange in Arbeit gewesenen englischen Uebersetzung und 
Erläuterung dieses LB.: An Introduction to the canonical Scriptures of the old T. translated from the German of De Wette with notes and an appendix by Theod. Parker. 2 Vls. Boston 1844. -

Basel Anf. Jul. 1844.

Der Verfasser.

\section{Vorwort des Herausgebers zur achten Ausgabe.}

Die Neuherausgabe des Werkes eines verstorbenen Autors wird eine verschiedene sein, je nachden das zu edirende Werk ein nachgelassenes, nach dem Tode des Verfassers tiberall zum ersten Male an's Licht tretendes ist, oder aber bereits seit längerer Zeit öffentlich vorliegt und lediglich aus irgend welchen Gründen neu aufgelegt werden soll. Ist im ersteren Falle die möglichst getreue Wiedergabe des Wortlautes der ursprunglichen Conception des Autors geboten, so wird dagegen in dem anderen Falle der Herausgeber zugleich auch darauf sein Augenmerk zu richten haben, das neu aufzulegende Werk den inzwischen gewonnenen Fortschritten der Wissenschaft gemäss herzurichten, beziehungsweise diesen gemäss umzugestalten. Diese Forderung wird um so dringender an den Herausgeber herantreten, ein je weiterer Zwischenraum zwischen der Ausgabe letzter Hand und der Zeit der Neuherausgabe zwischeninneliegt. In einem solchen Falle sich lediglich auf literarische Nachträge oder Ausmerzung von offenbaren Versehen beschrănken zu wollen, scheint nicht angezeigt. Als demgemäss die Verlagshandlung an den Unter- 